\title{
Financial Risk Analysis of listed Commercial Banks in China Based on Interest Rate Marketization
}

\author{
shenpan \\ School Of Economics and Commerce South China University Of Technology \\ shenpan0211@163.com
}

Keywords: rate of interest, deposits and loans business, financial exposure.

\begin{abstract}
Interest rate marketization is the inevitable outcome of the development of a country's financial industry, along with the advancement of marketization of interest rate in our country, our country commercial bank interest rate marketization brings the huge challenge and severe shock At present, the main business of commercial Banks mainly deposit and loan business, loan business is sensitive to interest rate changes, interest rate changes will directly affect the assets and liabilities of commercial Banks in China, so as to affect the revenue and profits of commercial Banks So the influence of interest rate marketization of commercial Banks in China is very large.
\end{abstract}

\section{利率市场化下我国上市商业银行财务风险分析 \\ 沈盼 \\ 华南理工大学经济与贸易学院, 广州, 广东, 中国 shenpan0211@163.com}

关键词：利率；存贷业务；财务风险

中文摘要: 利率市场化是一国金融业发展的必然结果，随着我国利率市场化的推进，我国商 业银行面临利率市场化带来的巨大挑战和严重冲击。目前我国商业银行的主营业务主要是存 款业务和贷款业务, 存贷业务对利率变动十分敏感, 利率变动会直接影响我国商业银行的资 产负债, 从而影响到商业银行的收入和利润。所以利率市场化对我国商业银行的影响十分巨 大。

\section{1. 利率市场化对我国上市商业银行的挑战}

\section{1 对商业银行存贷款业务的影响:}

目前，我国商业银行的资产业务主要是贷款业务，负债业务主要是存款业务。商业银行 最大收入仍然是传统利息收入，占其总利润收入的七八成，是其赖以生存的利润来源。最近 三年，五大国有银行（工、农、中、建、交）利息净收入和营业收入比均达到 $70 \%$ 以上，其 中农业银行和交通银行利息占比已经达到 $80 \%$ 。股份制银行利息收入占总收入比重普遍比国 有银行稍高, 城市商业银行利差收入占比最高。利率市场化后, 商业银行为了抢占市场份额, 争夺存款, 势必会引起存款利率上升。而为了不损失自身利润, 尽可能发放贷款, 又必然会 降低贷款利率，从而使得商业银行存贷利差缩小，恶化银行的财务状况，引发财务风险。

\section{2 对商业银行的客户结构和传统业务的影响:}

目前我国中小企业的融资主要是通过信贷获得支持。一般情况下，单位贷款处理成本随 着贷款规模的上升而下降, 但是, 中小企业贷款不具有规模效应, 出于成本收入考虑, 大型 
金融机构更愿意把资金贷给规模更大的企业。在利率市场化改革之前，中小企业融资难现象 的普遍发生。在利率市场化的条件下, 信用良好的大型企业会转向寻求贷款利率最低的银行, 使得商业银行流失部分客户，只为大企业提供融资服务的渠道日益缩小，而为中小企业提供 融资逐步成为商业银行发展的内在需求, 成为我国银行业客户结构转变的重要方向和业务增 长点。

\section{3 对商业银行资本补充渠道的影响:}

银行资本补充渠道主要是通过内源融资和外源融资两种方式。利率市场化条件下，使得 利差收入逐步缩窄, 盈利能力减弱, 商业银行依靠留存收益的内源性资本补充能力也在逐渐 下降。在内源融资受到较大影响的情况下, 要保证商业银行的资本充足率，应该寻求多样化 的融资渠道。

\section{2. 上市商业银行财务指标的分析与构建}

利率市场化对商业银行的影响最终会体现在财务报表中，通过对财务数据的分析，选取 适当的财务指标来评价利率市场化对商业银行财务风险的影响。

商业银行的财务风险主要分为: 流动性风险、资产质量风险、盈利能力水平

和资本充足程度。

\section{1 商业银行财务指标的构建}

在银监会2004年公布的《股份制商业银行风险评级体系》中，把商业银行的风险评价的 类别概括为资本充足状况评价、资产安全状况评价、管理状况评价、盈利状况评价、流动性 状况评价和市场风险敏感性状况评价六个方面。由于管理状况指标不能量化, 不能通过数据 表现出来, 所以本文剔除管理状况指标。另外, 因为本文研究的是利率市场化对我国上市商 业银行财务风险的影响, 利率变化最终将通过财务风险反映出来, 所以剔除市场风险敏感性 状况指标。上市商业银行的财务指标最终选取流动性风险指标、资产质量风险指标、盈利能 力水平指标和资本充足程度指标四个方面。

表 $1:$ 变量定义

\begin{tabular}{llll}
\hline 变量 & 表示 & 变量 & 表示 \\
\hline 资本充足率 & $\mathrm{X} 1$ & 正常贷款迁徙率 & X6 \\
核心资本充足率 & $\mathrm{X} 2$ & 成本收入比例 & X7 \\
不良贷款率 & $\mathrm{X} 3$ & 资产利润率 & X8 \\
拨备覆盖率 & $\mathrm{X} 4$ & 流动比例 & X9 \\
单一最大客户贷款比率 & $\mathrm{X} 5$ & 存贷比 & X10 \\
\hline
\end{tabular}

\section{2 上市商业银行财务风险的评价}

根据构建的财务风险评价指标，对我国16家上市商业银行进行利率敏感性分析，并运用 因子分析法对我国上市商业银行进行财务风险分析。

因子分析法

设有原始变量 $\mathrm{X}=\left(x_{1}, x_{2}, x_{3}, \ldots x_{p}\right)$, 主成分 $\mathrm{Z}=\left(z_{1}, z_{2}, z_{3}, \ldots, z_{m}\right)$, 且均值向量 $\mathrm{E}(Z)=0$, 即各分量相互独立, 随机变量 $\mathrm{E}=\left(e_{1}, e_{2}, e_{3}, \ldots, e_{p}\right), \mathrm{E}(\mathrm{E})=0$, 各分量之间相互独立, 因子与 初始变量之间的关系表述为:

$$
\begin{aligned}
& x_{1}=a_{11} z_{1}+a_{12} z_{2}+\cdots+a_{1 m} z_{m}+e_{1} \\
& x_{2}=a_{21} z_{2}+a_{22} z_{2}+\ldots+a_{2 m} z_{m}+e_{2} \\
& \quad \cdots \cdots . \\
& x_{p}=a_{p 1} z_{1}+a_{p 2} z_{2}+\ldots+a_{p m} z_{m}+e_{p}
\end{aligned}
$$


其中, $z_{j}(j=1,2, \ldots, m)$ 对各分量 $x_{i}(i=1,2, \ldots, p)$ 都有作用, 称为公共因子, 是不可观测的 随机变量; $a_{i j}(i=1,2, \ldots, p, j=1,2, \ldots, m)$ 称为因子载荷矩阵; $\mathrm{A}=\left(a_{i j}\right)$ 称为因子载荷矩阵; 而 $e_{i}$ 只对 $x_{i}$ 起作用, 称为特殊因子, 是不能被前 $\mathrm{m}$ 个公共因子包含的部分, 并且满足: $(1) \mathrm{E}(\mathrm{z})=0$ $\mathrm{D}(\mathrm{z})=\mathrm{I} ; \quad$ （2） $\mathrm{E}(\mathrm{e})=0 \quad \mathrm{D}(\mathrm{e})=\operatorname{diag}\left(\sigma_{12}, \sigma_{22}, \ldots, \sigma_{\mathrm{p} 2}\right) ; \quad(3) \operatorname{Cov}\left(z_{j}, e_{i}\right)=0 \quad(\mathrm{i}=1,2, \cdots \mathrm{p}) 。$

本文数据来源于我国16家上市商业银行的年报, 选取了 2014 年的相关指标的数据, 进行 因子分析。

(1) KMO和Bartlett检验。从下表可知, KMO统计量为 0.601 大于 0.5 , 表明数据之间存在 强相关性, Bartlett检验显著性明显, 表明适合使用因子分析法。

表2: KM0 和 Bartlett 的检验

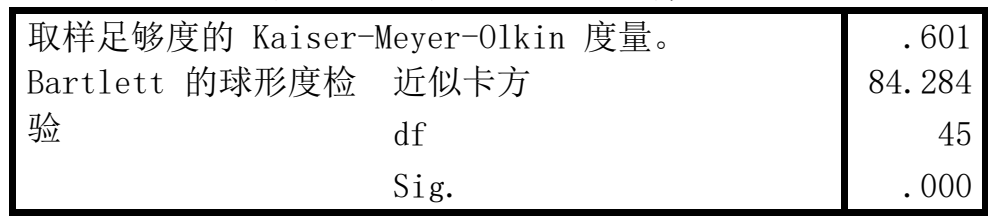

（2）原始变量的公因子方差均超过 0.5 , 其中超过一半的公因子方差超过了 0.7 , 反映出 各变量之间具有较高的相关性，因此主因子能够反映出大多数变量的信息。

表3: 公因子方差

\begin{tabular}{|l|c|c|}
\hline & 初始 & 提取 \\
\hline $\mathrm{X} 1$ & 1.000 & .954 \\
$\mathrm{X} 2$ & 1.000 & .881 \\
$\mathrm{X} 3$ & 1.000 & .654 \\
$\mathrm{X} 4$ & 1.000 & .721 \\
$\mathrm{X} 5$ & 1.000 & .654 \\
$\mathrm{X} 6$ & 1.000 & .796 \\
$\mathrm{X} 7$ & 1.000 & .899 \\
$\mathrm{X} 8$ & 1.000 & .674 \\
$\mathrm{X} 9$ & 1.000 & .510 \\
$\mathrm{X} 10$ & 1.000 & .880 \\
\hline
\end{tabular}

选取主成分分析法提取主因子。按照特征值大于 1 , 因子解释方差大于 $70 \%$ 提取主因子的 原则提取主因子。前四个因子累计方差贡献率为 $76.223 \%$, 表明这三个因子包含了所有 10 个因 子的 $76.223 \%$ 的信息，可以选择这四个因子为主因子。

表 4 : 解释的总方差

\begin{tabular}{|c|c|c|c|c|c|c|c|c|c|}
\hline \multirow[b]{2}{*}{ 成份 } & \multicolumn{3}{|c|}{ 初始特征值 } & \multicolumn{3}{|c|}{ 提取平方和载入 } & \multicolumn{3}{|c|}{ 旋转平方和载入 } \\
\hline & 合计 & 方差的 $\%$ & 累积 \% & 合计 & 方差的 $\%$ & 累积 \% & 合计 & 方差的 \% & 累积 \% \\
\hline 1 & 3.284 & 32.841 & 32.841 & 3.284 & 32.841 & 32.841 & 3.239 & 32.391 & 32.391 \\
\hline 2 & 2.793 & 27.931 & 60.772 & 2.793 & 27. 931 & 60.772 & 2.505 & 25.050 & 57.441 \\
\hline 3 & 1. 545 & 15. 451 & 76.223 & 1.545 & 15. 451 & 76. 223 & 1. 878 & 18. 782 & 76. 223 \\
\hline 4 & .652 & 6. 524 & 82.747 & & & & & & \\
\hline 5 & .543 & 5.434 & 88.181 & & & & & & \\
\hline 6 & .506 & 5.056 & 93.237 & & & & & & \\
\hline 7 & .400 & 4. 005 & 97.242 & & & & & & \\
\hline 8 & 157 & 1.575 & 98.817 & & & & & & \\
\hline 9 & .089 & .890 & 99.707 & & & & & & \\
\hline 10 & .029 & 293 & 100.000 & & & & & & \\
\hline
\end{tabular}

从上表可以看出排在最前面的 3 个因子为最重要的因子，表明 10 个相关指标可以用前 3 个 主要因子解释。因此, 本文以前四个指标作为评价银行风险的主因子, 这四个因子的特征值 均大于 1 , 方差的累计贡献率综合为 $76.223 \%$ 。 
表5: 旋转成份矩阵

\begin{tabular}{|l|r|r|r|}
\hline \multirow{2}{*}{} & \multicolumn{3}{|c|}{ 成份 } \\
\cline { 2 - 4 } & 1 & 2 & 3 \\
\hline X1 & .852 & .458 & .136 \\
X2 & .805 & .481 & .036 \\
X4 & .085 & .804 & -.007 \\
X5 & .105 & -.465 & .702 \\
X6 & -.217 & -.411 & .661 \\
X7 & -.772 & .415 & -.167 \\
X8 & -.749 & .581 & -.005 \\
X9 & .797 & .034 & -.194 \\
X10 & .013 & .682 & -.212 \\
\hline
\end{tabular}

主因子Z1在（资本充足率）、（核心资本充足率）上有较大载荷, 该因子初始变量方 差贡献率为 $32.391 \%$, 表明资本充足情况是决定商业银行财务风险最关键性的因素。主因子 Z2在（不良贷款率）上有较大载荷, 该因子初始变量的方差贡献率为 $25.050 \%$, 反映了银行 资产质量是影响银行财务风险的重要因素。主因子Z3在（存贷比）上有较大载荷, 该因子初 始变量方程贡献率为 $18.782 \%$, 表明商业银行流动性也是影响商业银行财务风险的重要因素。 通过将旋转后的载荷矩阵标准化得到的因子得分系数矩阵来描述主因子与原始变量间的关 系。

表6: 成份得分系数矩阵

\begin{tabular}{|l|r|r|r|}
\hline \multirow{2}{*}{} & \multicolumn{3}{|c|}{ 成份 } \\
\cline { 2 - 4 } & 1 & 2 & 3 \\
\hline X1 X2 & .248 & .188 & .109 \\
X3 & .236 & .186 & .056 \\
X4 & .003 & .341 & .093 \\
X5 & .025 & -.115 & .339 \\
X6 & -.075 & -.087 & .332 \\
X7 & -.248 & .180 & -.020 \\
X8 & -.250 & .270 & .092 \\
X9 & .253 & -.033 & -.130 \\
X10 & -.010 & .265 & -.036 \\
X & .006 & -.210 & -.542 \\
\hline
\end{tabular}

根据成分得分矩阵，可以得到四个主因子的得分函数如下：

$z_{1}=0.248 x_{1}+0.236 x_{2}+0.003 x_{3}+0.025 x_{4}-0.075 x_{5}-0.248 x_{6}-0.250 x_{7}$

$+0.253 x_{8}-0.010 x_{9}+0.006 x_{10}$

$z_{2}=0.188 x_{1}+0.186 x_{2}+0.341 x_{3}-0.115 x_{4}-0.087 x_{5}+0.180 x_{6}+0.270 x_{7}$

$-0.033 x_{8}+0.265 x_{9}-0.210 x_{10}$

$z_{3}=0.109 x_{1}+0.056 x_{2}+0.093 x_{3}+0.339 x_{4}+0.332 x_{5}-0.020 x_{6}+0.092 x_{7}$

$-0.130 x_{8}-0.036 x_{9}-0.542 x_{10}$

根据主因子得分及其对初始变量的贡献率可以计算综合得分, 其表达如下:

$Z=0.32391 z_{1}+0.25050 z_{2}+0.18782 z_{3}$

运用公式，对我国上市 16 家商业银行的主因子的综合因子计算其得分，因子得分数值越 大，其风险越小，说明其抗击风险冲击能力越高。下表对16家商业银行的2014年的风险性进 行计算。 
表7: 综合得分表

\begin{tabular}{|c|c|c|c|c|c|c|c|c|}
\hline \multirow{2}{*}{ 银行名称 } & \multicolumn{6}{|c|}{ 主成分得分 } & \multirow{2}{*}{ 综合得分 Z } & \multirow{2}{*}{ 排名 } \\
\hline & $\mathrm{Z1}$ & 排名 & $\mathrm{Z2}$ & 排名 & Z3 & 排名 & & \\
\hline 农业银行 & 4. 58667 & 7 & -29.216 & 13 & 95.86666 & 2 & 12. 17275 & 1 \\
\hline 北京银行 & 7. 76362 & 1 & -39.8109 & 16 & 98. 49488 & 1 & 11.0414 & 2 \\
\hline 兴业银行 & 6. 3519 & 2 & -33.3331 & 15 & 90.85503 & 3 & 10.7719 & 3 \\
\hline 南京银行 & 4. 973 & 4 & -21.3062 & 8 & 74.9344 & 4 & 10. 34778 & 4 \\
\hline 浦发银行 & 6. 08514 & 3 & -32.7361 & 14 & 72.62632 & 5 & 7. 41131 & 5 \\
\hline 宁波银行 & 2. 14032 & 13 & -17.0711 & 6 & 57. 22335 & 8 & 7. 164655 & 6 \\
\hline 建设银行 & 4. 73165 & 6 & -20.5636 & 7 & 57.30825 & 7 & 7. 145077 & 7 \\
\hline 华夏银行 & 1. 37658 & 15 & -26.9034 & 12 & 70.52111 & 6 & 6. 951874 & 8 \\
\hline 招商银行 & 2. 46479 & 12 & -16.8559 & 5 & 53. 16483 & 10 & 6.561383 & 9 \\
\hline 工商银行 & 4. 89867 & 5 & -23.3456 & 10 & 55.86439 & 9 & 6.231118 & 10 \\
\hline 中国银行 & 3. 15322 & 8 & -16.0685 & 4 & 42.02569 & 13 & 4. 889475 & 11 \\
\hline 民生银行 & 2.7144 & 10 & -24.5884 & 11 & 52.60258 & 11 & 4. 599641 & 12 \\
\hline 光大银行 & 2. 57752 & 11 & -21.6125 & 9 & 47. 14937 & 12 & 4. 276538 & 13 \\
\hline 交通银行 & 3. 04304 & 9 & -14.8826 & 2 & 35.93006 & 14 & 4. 005969 & 14 \\
\hline 平安银行 & -2.09003 & 16 & -9.31767 & 1 & 35. 35193 & 15 & 3. 628742 & 15 \\
\hline 中信银行 & 1. 84866 & 14 & -14.9269 & 3 & 34.91455 & 16 & 3. 417264 & 16 \\
\hline
\end{tabular}

运用因子分析法对 16 家上市商业银行 2014 年的财务数据进行分析，农业银行的财务风险 水平最低, 这与其较低的存贷比密切相关。资料显示, 农业银行 2014 年存贷比为 $57.40 \%$, 这 弥补了其在资本充足性方面的不足。另外得分比较高的银行分别是北京银行、兴业银行、南 京银行和浦发银行, 其资本充足指标、盈利性指标和流动性指标排名都比较靠前, 而排名靠 后的交通银行、平安银行和中信银行, 资本充足率和盈利能力都比较低, 存贷比也都低于其 他银行, 说明资本充足状况在商业银行中起着关键性作用。从商业银行的规模来看, 城市商 业银行财务风险最小，大型国有商业银行其次，中小股份制商业银行财务风险最大。

进一步分析发现, 我国国有四大商业银行在资产质量方面的风险普遍较大，国有商业银 行改革虽取得了一定成效, 但在资产管理方面仍有很长的路要走, 积极采取措施加强不良贷 款回收、清理仍是国有商业银行面临的重要课题。中小股份制商业银行资本充足率不高是普 遍存在的问题。

\section{3. 上市商业银行财务风险的政策建议}

对我国上市商业银行的财务风险影响因素从高到低为, 资产充足因素, 资产质量因素、 流动性因素和盈利性因素。通过上市商业银行财务风险因子分析得出, 对上市商业银行财务 风险影响最大的因素资本充足因素, 在利率市场化条件下, 上市商业银行面临较大的资本压 力，面临着资本充足风险。

3.1 提升、维持良好的资本充足水平

较高的资本充足水平可以增强商业银行抵御风险的能力。商业银行自身也应该意识到资 本的重要性,通过多种途径、不同方式提高资本水平。另外, 风险资产也会影响商业银行的资 本充足水平，甚至会引发财务风险，因此商业银行应结合自身的业务特点和资产状况及时调 整资产结构, 优化资源配置, 减少风险资产所占的比重, 完善资本结构, 建立资本补充机制。 总体上银改善商业银行自我管理经营能力,提高竞争力, 减少财务风险。

\section{2 继续消化不良贷款,降低不良贷款率}

总体而言我国银行业的不良贷款和不良贷款率均呈现下降的趋势，但与发达国家相比我 国的不良贷款率仍然偏高, 不良贷款仍然有待于大幅降低。商业银行应对贷款业务进行严格 的规范, 提高信贷质量, 降低不良贷款率, 防止资产质量风险的发生。要对贷款客户的财务 状况, 资产情况等方面进行详细的检查, 不能为了达到贷款额度目标盲目放贷, 提高贷款质 
量; 要完善贷款审批、授信和内部审计制度，对贷款资产进行动态监测，对贷款进行严格的 管理。

\section{3拓展获利渠道,提高获利能力}

近5年来，我国商业银行的资产利润率基本在1.5\%以下,总体而言,获利能力较差。主要原 因还是我国商业银行获利方式单一,虽然近些年中间业务得到了一定程度的发展,但是利息收 入仍然是商业银行利润的主要源泉,利润高度依赖于信贷规模。伴随着利率市场化的推进，存 贷利差缩小，会压缩商业银行的利润水平，所以银行应该努力拓展多种业务渠道、降低经营 成本, 提高获利能力, 增强抵抗风险的能力。

\section{4加强流动性管理}

从商业银行自身来看, 各商业银行应继续严格执行存贷比的相关监管要求, 稳健持续经 营。以存贷比为依据来确定各项业务中的操作是否合理, 用来督促银行维持经营的稳定和发 展的长期性。同时，可以通过货币市场和资本市场为商业银行提供资金来源，改善商业银行 的流动性。

\section{References}

[1] De Nicolo G. Size , charter value and risk in banking: an international perspective [R]. International Financial Discussion Paper, Board of Governors of the Federal Reserve System, 2001.

[2] Ka1ari J, Dennis G, Hwan S, Michele C. Predicting large US commercial bank failures [J]. Journal of Economics and Business, 2002, 54:361-387.

[3] Anthony Saunders,Elizabeth Strock,Nickolaos G Travlos.Ownership Structure, Deregulation, and Bank Risk Taking. Journal of Finance, The . 1990.

[4] De Nicolo G.Size, charter value and risk in banking: an international perspective. InternationalFinancial Discussion Paper . 2001.

[5] J. Kolari,D. Glennon,H. Shin,M. Caputo.Predicting large US commercial bank failures. J. Econ. Bus . 2002.

[6] Choudhry Tanveer Shehzada,Jakob De Haan.Financial Liberalization and BankingCrises. Faculty of Economics and Business . 2008.

[7] Ohlson J.A.Financial Ratios and the Probabilistic Prediction of Bankruptcy. Journal of Operation Research . 1980.

[8] The interaction and volatility asymmetry of unexpected returns in the greater China stock markets[J]. Global Finance Journal . 2000 (1)

[9] Raj Aggarwal,B. Philip Jeon,Xinlei Zhao. Bank Exposure to Interest Rate Risks During Financial Liberalization: Evidence from South Korea[J]. Asia-Pacific Financial Markets . 2006 (1).

[10]Anthony G. Cornyn,,Robert A .Klein,,Jess Lederman.Controlling and Managing Interest Rate Risk. . 1997. 